\title{
Produtividade do inhame em função de fertilização orgânica e mineral e de épocas de colheita.
}

\author{
Ademar P. Oliveira ${ }^{1}$; Pedro A. Freitas Neto ${ }^{1}$; Elson S. Santos ${ }^{2}$ \\ ${ }^{1}$ UFPB - CCA, C. Postal 02, 58.397-000 Areia - PB; ²EMEPA, 58.013-290, João Pessoa - PB. Email: ademar@ @ca.ufpb.br
}

\begin{abstract}
RESUMO
Na Empresa Estadual de Pesquisa Agropecuária da Paraíba em João Pessoa, foi instalado um experimento em solo Podzólico Vermelho-Amarelo de textura arenosa, com o objetivo de se avaliar a produtividade do inhame Dioscorea cayennensis variedade Da Costa, em função de fonte e doses de matéria orgânica, de adubação mineral (NPK) e de épocas de colheita. O delineamento experimental utilizado foi blocos casualizados, com parcelas subdivididas em arranjo fatorial $2 \times 4+2$, com quatro repetições, estudando-se nas parcelas principais o efeito de épocas de colheita (sete e nove meses após o plantio) e nas subparcelas, oito tratamentos formados por quatro doses de esterco bovino $(5 ; 10 ; 15$ e 20 t/ha) e por quatro de esterco de galinha $(2,8 ; 5,6 ; 8,4$ e 11,2 t/ha), associadas a 100-120$60 \mathrm{~kg} / \mathrm{ha}$ de $\mathrm{N}-\mathrm{P}_{2} \mathrm{O}_{5}-\mathrm{K}_{2} \mathrm{O}$ e dois tratamentos adicionais (testemunha absoluta e adubação mineral isolada). O emprego de matéria orgânica proporcionou incremento de 3,8 t/ha na produtividade do inhame na colheita aos nove meses. A produtividade alcançada com esterco bovino, aos sete meses, superou significativamente em 1,9 t/ ha a produtividade obtida com esterco de galinha. Aos nove meses, o esterco de galinha proporcionou aumento significativo de 2,0 t/ha na produtividade em relação à obtida com esterco bovino. A produtividade de inhame obtida com adubação mineral isolada aos sete e nove meses após o plantio, superou significativamente a testemunha em 7,7 e 4,4 t/ha, respectivamente. As doses de 13,3 e 12,6 t/ha de esterco bovino mais NPK foram responsáveis pela máxima produtividade de inhame (18 t/ha) colhido aos sete meses e $20 \mathrm{t} / \mathrm{ha}$, colhido aos nove meses após o plantio, respectivamente, enquanto a dose de 7,0 t/ha de esterco de galinha proporcionou produtividade máxima de $15 \mathrm{t} / \mathrm{ha}$ de inhame colhido aos sete meses e de $22 \mathrm{t} / \mathrm{ha}$ colhido aos nove meses após o plantio. A produtividade média geral obtida na colheita aos nove meses após o plantio alcançou $18 \mathrm{t} / \mathrm{ha}$ superando, significativamente, em 19,5\% (3,5 t/ha) a média de 14,5 t/ha obtida na colheita aos sete meses.
\end{abstract}

Palavras-chave: Dioscorea cayennensis Lam, adubação orgânica, adubação mineral, idade, rendimento.

\begin{abstract}
Yam yield as a result of organic, mineral fertilization and harvest time.
\end{abstract}

An experiment was carried out using Red-yellow Podzolic soil of sandy texture, in Paraíba, (Brazil), to evaluate the yield of Dioscorea cayennensis yam, cv. Da Costa cultivated with different sources and levels of organic matter and mineral fertilization (NPK). The experimental design was of randomized blocks with split-plots in a factorial scheme of $2 \times 4+2$ and four replications. In the main plots was studied the harvest time (seven and nine months after planting date (MPD)) and, in the sub-plots four levels of cattle manure $(5,10,15,20 \mathrm{t} / \mathrm{ha})$ and four levels of chicken manure $(2.8 ; 5.6 ; 8.4$; $11.2 \mathrm{t} / \mathrm{ha}$ ), associated to $100-120-60 \mathrm{~kg} / \mathrm{ha}$ of $\mathrm{N}-\mathrm{P}_{2} \mathrm{O}_{5}-\mathrm{K}_{2} \mathrm{O}$ and two additional treatments (control and isolated mineral fertilization). Organic matter, increased in $3.8 \mathrm{t} / \mathrm{ha}$ the yield of yam harvested after nine MPD. Cattle manure surpassed significantly by 1.9 t/ha the yield obtained with the addition of chicken manure, seven MPD. Nine MPD, the addition of chicken manure resulted in a significant yield increase $(2.0 \mathrm{t} / \mathrm{ha})$ when compared to treatments with addition of cattle manure. Mineral fertilization alone resulted in significant yield increases seven $(7.7 \mathrm{t} / \mathrm{ha})$ and nine $(4.4 \mathrm{t} / \mathrm{ha})$ MPD. Cattle manure (13.3 and 12.6 t/ha) plus NPK was responsible for the maximum yam yield, (18 t/ha) when harvested at seven MPD (20 t/ ha), and nine MPD, while the level of $7.0 \mathrm{t} / \mathrm{ha}$ of chicken manure resulted in maximum yam yield (15 t/ha) at seven ( $22 \mathrm{t} / \mathrm{ha})$ and nine MPD. Average yield when harvesting nine MPD (18.0 t/ha) surpassed significantly, in $19.5 \%$ (3.5 t/ha) the average of $14.5 \mathrm{t} / \mathrm{ha}$ obtained at seven MPD.

Keywords: Dioscorea cayennensis Lam, organic fertilization, mineral fertilization, age, yield.

\section{(Aceito para publicação em 02 de abril de 2.001)}

$\mathrm{O}$ inhame (Dioscorea cayennensis Lam.) também conhecido por Cará-da-Costa, alcança grande importância sócio-econômica na região Nordeste. Os Estados de Pernambuco e Paraíba são considerados os maiores produtores, por apresentarem condições de ambiente favorável ao seu cultivo (Santos, 1996). Geralmente, é cultivado em solos arenosos, com baixo teor de matéria orgânica (Buckman \& Brady,
1976; Santos, 1996). Freqüentemente são empregados materiais orgânicos na sua adubação sendo ainda pouco estudada a relação entre a fertilização orgânica e a produtividade. A matéria orgânica presente no solo, por meio do processo de mineralização, fornece principalmente nitrogênio, fósforo, enxofre e micronutrientes para as plantas e microflora do solo (Kiehl, 1985; Oliveira Filho et al., 1987).
Para Ferguson \& Haynes (1970), o rendimento do inhame está diretamente relacionado com o suprimento de nutrientes. A lenta decomposição de materiais orgânicos promove o fornecimento contínuo de elementos essenciais à cultura. Altas produções são obtidas quando os nutrientes estão disponíveis às plantas em todos os estádios de crescimento e nas quantidades certas (Kemmler, 1974). 
Santos et al. (1998) verificaram que o emprego de 12,5 tha de esterco bovino e de 6 t/ha de esterco de galinha proporcionaram resultados satisfatórios na produtividade de inhame; por outro lado, o esterco caprino, a torta de filtro de usina e a casca de coco triturada, não proporcionaram ganhos de rendimentos. Também Matias \& Almeida (1985) obtiveram elevada produtividade do inhame com $10 \mathrm{t} /$ ha de esterco bovino na ausência de adubação mineral. Efeito significativo no aumento da produtividade do inhame tem sido observado utilizando-se esterco tanto isolado quanto em associação com a adubação mineral (Matias, 1989).

Com relação ao emprego de adubo mineral, embora algumas generalizações possam ser feitas, os inhames requerem nível elevado de nutrientes (Martin, 1972). Estudos desenvolvidos sobre a absorção de nutrientes por inhame mostraram que o nitrogênio e o potássio são os principais nutrientes removidos pela cultura, seguidos do cálcio e do fósforo e que ocorrem mudanças notáveis na composição mineral das folhas durante suas fases de crescimento, com o conteúdo de $\mathrm{N}$ e $\mathrm{K}$ aumentando continuamente até o quinto mês após o plantio e atingindo o seu pico durante o sexto mês para depois diminuir, correspondendo assim ao tempo de máxima atividade de crescimento e de maior demanda por nutrientes (Obigbesan \& Agboola, 1978).

No inhame, os nutrientes desempenham papel importante em cada fase do seu desenvolvimento. O nitrogênio é importante durante a primeira metade do seu ciclo para dar suporte ao crescimento vegetativo, o potássio e o fósforo a partir da metade do ciclo, por participarem do processo de tuberização (Martin, 1976). No entanto, Ferguson \& Haynes (1970) e Souto (1989) verificaram respostas relativamente baixas do inhame ao emprego do nitrogênio; ainda o potássio e o fósforo não influenciaram a produção de túberas.

O presente trabalho teve como objetivo avaliar a produtividade do inhame Dioscorea Cayennensis, em função de fontes e doses de matéria orgânica, adubo mineral e de épocas de colheita.

\section{MATERIAL E MÉTODOS}

Foi realizado um experimento em campo, em solo Podzólico Vermelho-
Amarelo, textura arenosa, na Empresa Estadual de Pesquisa Agropecuária da Paraíba (EMEPA-PB), em João Pessoa, entre setembro de 1998 e junho de 1999. $\mathrm{A}$ análise química do solo indicou: $\mathrm{pH}$ $\mathrm{H}_{2} \mathrm{O}(1: 2: 5)=4,8 ; \mathrm{P}=10,24 \mathrm{mg} / \mathrm{dm}^{3} ; \mathrm{K}$ $=25,00 \mathrm{mg} / \mathrm{dm}^{3} ; \mathrm{Na}=0,04 \mathrm{cmol} / \mathrm{dm}^{3}$; $\mathrm{H}^{+}+\mathrm{Al}^{+3}=3,55 \mathrm{cmol} / \mathrm{dm}^{3} ; \mathrm{Al}^{+3}=0,39$ $\mathrm{cmol} / \mathrm{dm}^{3} ; \mathrm{Ca}^{+2}=0,50 \mathrm{cmol} / \mathrm{dm}^{3} ; \mathrm{Mg}^{+2}$ $=0,20 \mathrm{cmol} / \mathrm{dm}^{3}$, matéria orgânica $=$ $7,96 \mathrm{~g} / \mathrm{dm}^{3} ;$ CTC $=4,35 \mathrm{cmol} / \mathrm{dm}^{3}$; Areia $=55,0 \mathrm{dag} / \mathrm{kg} ;$ Silte $=12,9 \mathrm{dag} /$ $\mathrm{kg}$; e argila $=2,2 \mathrm{dag} / \mathrm{kg}$.

O esterco bovino e de galinha apresentaram, respectivamente, a seguinte composição química: $\mathrm{P}_{2} \mathrm{O}_{5}=4,3$ e 17,18 $\mathrm{g} / \mathrm{kg} ; \mathrm{K}_{2} \mathrm{O}=9,75$ e $17,25 \mathrm{~g} / \mathrm{kg} ; \mathrm{C}=$ 105,61 e $153,83 \mathrm{~g} / \mathrm{dm}^{3} ; \mathrm{N}=9,82$ e 22,09 $\mathrm{g} / \mathrm{dm}^{3}$; relação $\mathrm{C} / \mathrm{N}=10,75$ e 6,96 ; matéria orgânica $=182,07$ e $265,20 \mathrm{~g} / \mathrm{dm}^{3}$.

$\mathrm{O}$ experimento foi conduzido em parcelas subdivididas, com duas épocas de colheita nas parcelas (sete e noves meses após o plantio) e, nas subparcelas, oito tratamentos formados por quatro doses de esterco bovino $(5,10,15,20 \mathrm{t} /$ ha) e de esterco de galinha $(2,8 ; 5,6 ; 8,4$; $11,2 \mathrm{t} / \mathrm{ha}$ ) associados a $100-120-60 \mathrm{~kg} /$ ha de $\mathrm{N}-\mathrm{P}_{2} \mathrm{O}_{5}-\mathrm{K}_{2} \mathrm{O}$, além dos tratamentos testemunha absoluta e testemunha com adubação mineral isolada, em blocos casualizados, com quatro repetições. A adubação mineral constou da aplicação de $36 \mathrm{~g} /$ planta de superfosfato triplo e de $21 \mathrm{~g} /$ planta de cloreto de potássio em adubação de plantio e de 7,5 g/planta de sulfato de amônio em adubação de cobertura, aos 120 dias após o plantio. As doses de esterco de galinha, foram definidas por meio da sua composição química em relação à do esterco bovino.

O solo foi preparado por meio de uma aração e duas gradagens e confecções de leirões com aproximadamente $0,50 \mathrm{~m}$ de altura, espaçado entre si de $1,20 \mathrm{~m}$. A unidade experimental foi composta por quatro leirões com 32 plantas, sendo cada um com 4,8 m de comprimento e oito plantas espaçadas de $0,60 \mathrm{~m}$, sendo consideradas doze plantas centrais, como úteis.

No plantio, empregaram-se túberassemente da cultivar Da Costa tratadas com solução de Benlate 500 (à dose de $200 \mathrm{~g}$ do produto comercial para 100 litros de água) e Nemacur (à dose de 250 g/100 litros de água). As mesmas foram plantadas, a $10 \mathrm{~cm}$ de profundidade do topo do leirão. As plantas foram tutoradas adotando-se o sistema de espaldeiramento.

Durante a condução do experimento foram realizadas, de acordo com a necessidade, capinas manuais com auxílio de enxadas, visando manter a área sempre limpa e livre da competição com plantas daninhas. Por ocasião das capinas, realizaram-se também amontoas objetivando manter os leirões bem formados e proteger as túberas contra o efeito dos raios solares. A cultura foi conduzida em regime de irrigação, empregando-se o sistema de aspersão convencional. Não foi observada a ocorrência de pragas e doenças, dispensando o uso de defensivos.

A produtividade de túberas foi obtida aos sete meses após o plantio, período caracterizado pelo término da floração com secamento das flores, através da colheita precoce ou "capação" e, aos nove meses, ocasião do amadurecimento das túberas. Os dados foram submetidos à análise de variância e as médias comparadas pelo teste Tukey, a 5\% de probabilidade. Também foram realizadas análises de regressão das doses de esterco bovino e de esterco de galinha, sendo selecionado para expressar a produtividade, o modelo significativo de maior ordem e com maior coeficiente de determinação.

\section{RESULTADOS E DISCUSSÃO}

Na tabela 1 constam as médias de produtividade de inhame, em função dos tratamentos orgânicos, mineral e das épocas de colheita. A análise comparativa pelo teste de Tukey, evidenciou que a produtividade alcançada com o emprego do esterco bovino superou significativamente em 1,9 t/ha a produtividade obtida com esterco de galinha para a colheita aos sete meses; entretanto, a produtividade com esterco bovino foi superada significativamente em 2,0 t/ha pelo esterco de galinha na colheita aos nove meses, tornando a diferença entre as médias das duas épocas colheita em função das fontes de matéria orgânica não significativa. Este fato pode ser explicado pela desigualdade nas taxas de mineralização promovidas pela 
Tabela 1. Produtividade de inhame (t/ha), em função de fontes de matéria orgânica, adubo mineral e épocas de colheita. João Pessoa, EMEPA, 1999.

\begin{tabular}{lcc}
\hline \multirow{2}{*}{ Tratamentos } & \multicolumn{2}{c}{ Épocas de colheita } \\
\cline { 2 - 3 } & $\mathbf{7}$ meses & $\mathbf{9}$ meses \\
\hline Médias de esterco bovino & $16,180 \mathrm{a}^{1}$ & $18,85 \mathrm{~b}$ \\
Média de esterco de galinha & $14,262 \mathrm{~b}$ & $20,87 \mathrm{a}$ \\
\hline Matéria orgânica x NPK & & \\
Matéria orgânica & $15,221 \mathrm{a}$ & $19,858 \mathrm{a}$ \\
NPK & $13,642 \mathrm{a}$ & $15,999 \mathrm{~b}$ \\
\hline NPK x Testemunha & & \\
NPK & $17,485 \mathrm{a}$ & $18,178 \mathrm{a}$ \\
Testemunha & $9,798 \mathrm{~b}$ & $13,819 \mathrm{~b}$ \\
\hline Média geral & 14,50 & 18,00 \\
\hline CV (\%) & 3,77 & 12,40 \\
\hline
\end{tabular}

${ }^{1}$ Médias seguidas da mesma letra nas colunas não diferem significativamente entre si, a 5\% de probabilidade pelo teste de Tukey

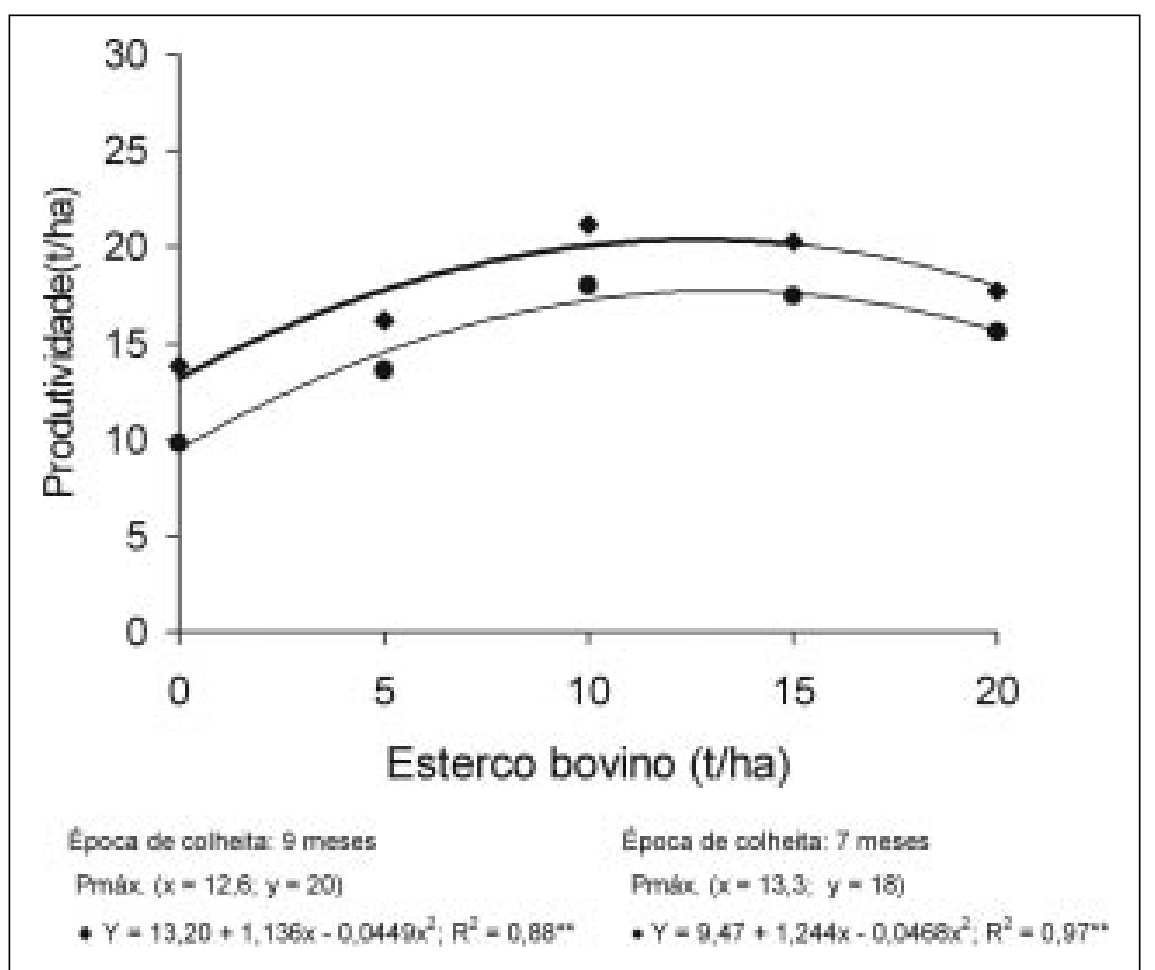

Figura 1. Produtividade de inhame, em função de doses de esterco bovino associadas à adubação mineral, em duas épocas de colheita. João Pessoa, EMEPA, 1999.

diferença entre as relações $\mathrm{C} / \mathrm{N}$ do esterco bovino e do esterco de galinha, em virtude da equivalência entre as doses desses fertilizantes.

Também pode-se verificar pela tabela 1 que houve incremento de 3,8 t/ha na produtividade do inhame promovido pela adição de matéria orgânica mais adubo mineral, na colheita aos nove meses. Elevação na produtividade de inhame com o emprego de matéria or- gânica também foi verificada por diversos autores (Mendes, 1982; Silva, 1983; Matias, 1989; Santos, 1996).

A produtividade do inhame com adubação mineral superou significativamente em 7,7 e 4,4 t/ha a testemunha absoluta quando as colheitas foram realizadas aos sete e nove meses após o plantio, respectivamente (Tabela 1). Estes resultados ressaltam a exigência de nutrientes minerais pelo inhame
(Martin, 1972) e sua importância no aumento do seu rendimento (Ferguson \& Haynes 1970; Martin, 1972; Souto, 1989; Santos 1996; Santos et al., 1998).

As respostas das doses de esterco bovino e de esterco de galinha acrescentados de NPK sobre a produtividade do inhame, ajustaram-se a modelos quadráticos, nas duas épocas de colheita. Pela derivação da equação de regressão (Figura 1), calcularam-se as doses de 13,3 e 12,6 t/ha de esterco bovino, como aquelas responsáveis pela máxima produtividade de inhame (18 t/ha) aos sete meses após o plantio e aos nove meses (20 t/ha), respectivamente. Para o esterco de galinha a dose de 7,0 t/ha foi responsável pela produtividade máxima de inhame de $15 \mathrm{t} / \mathrm{ha}$ aos sete meses após o plantio e de $22 \mathrm{t} / \mathrm{ha}$, aos nove meses, respectivamente (Figura 2). Resultados obtidos por Santos et al. (1998) mostraram que a produtividade de inhame respondeu de forma quadrática até a dose de 12,5 e 6,0 t/ha de esterco bovino e de galinha, respectivamente.

A adição de esterco bovino e de esterco de galinha, proporcionaram produtividade de inhame acima da média estabelecida por Santos (1996) em 12 t/ ha, para o Estado da Paraíba, indicando os benefícios do emprego de matéria orgânica no seu cultivo. Matias (1989) verificou efeito significativo do emprego de matéria orgânica sobre a produtividade de inhame aplicada de forma tanto isolada ou associada a adubos minerais, em à relação adubação mineral. Ferguson \& Haynes (1970) relataram que o efeito da matéria orgânica sobre $o$ rendimento do inhame está relacionado ao suprimento contínuo de nutrientes. Entretanto, altas produções somente podem ser obtidas quando os nutrientes estão disponíveis às plantas em todos os estádios de crescimento e nas quantidades adequadas (Kemmler, 1974). Portanto, neste estudo as fontes de matéria orgânica, juntamente com o adubo mineral supriram eficientemente as necessidades nutricionais do inhame.

Os efeitos positivos da adição da matéria orgânica sobre a produtividade de inhame devem-se, além do fornecimento de nutrientes, à sua ação na melhoria da capacidade de troca das bases, promovendo maior disponibilida- 
de de nutrientes para a planta por um longo período. Esses efeitos são mais acentuados em solos de baixa CTC, situação ocorrida no presente estudo. Khiel (1985) e Matos et al. (1997) observaram diferenças significativas no $\mathrm{pH}$, teores de $\mathrm{K}, \mathrm{Mg}$ e soma das bases em um solo Podzólico Vermelho-Amarelo Câmbico devido à adição de matéria orgânica.

Analisando-se as épocas de colheita (Tabela 1), a produtividade média geral de túberas obtida na colheita aos nove meses após o plantio alcançou 18,00 t/ha superando, significativamente, em 19,5\% (3,5 t/ha) a média obtida aos sete meses do plantio (14,50 t/ha), evidenciando o efeito promovido pelas épocas de colheita sobre este parâmetro. Normalmente a colheita precoce (sete meses após o plantio), resulta em produtividade menor. Contudo, pesquisa realizada por Mafra (1978) indica que esta diferença é compensada pela produção de túberas-semente que corresponde a aproximadamente $27 \%$ da produção total, obtida aos três meses após a colheita precoce ("capação").

\section{AGRADECIMENTOS}

Os autores agradecem à professora Sheila Costa de Farias pela correção do abstract.

\section{LITERATURA CITADA}

BUCKMAN, H.; BRADY, N.C. Natureza e propriedade dos solos. São Paulo: Freitas Bastos, 1976. $594 \mathrm{p}$.

FERGUSON, T.U.; HAYNES, P.H. The response of yams (Dioscorea sp.) to nitrogen, phosphorus, potassium and organic fertilizers. PROCEEDING. INTERNATIONAL SYMPOSIUM ROOT TUBER CROPS, v. 2, p. 93-96, 1970.

KEMMLER, G. Modern aspects of wheat manuring. International Potash Institute, 1974. 66 p. (Bulletin, 1).

KIEHL, E.J. Fertilizantes orgânicos. Piracicaba: Agronômica Ceres, 1985. 492 p.

MAFRA, R.C. Contribuição ao estudo da cultura do cará. Recife: Universidade Federal Rural de Pernambuco, 1978. 20 p.

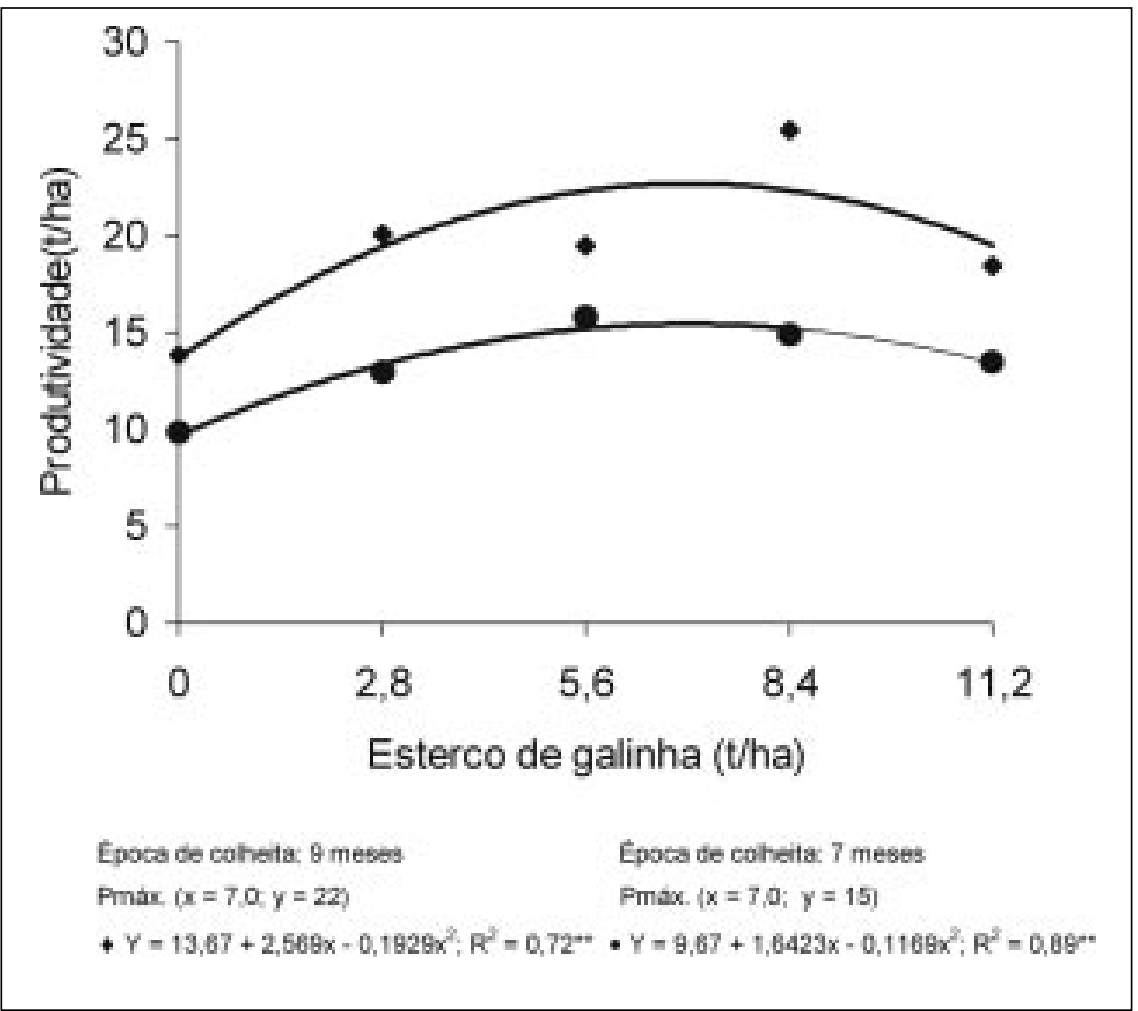

Figura 2. Produtividade de inhame, em função de doses de esterco de galinha associadas à adubação mineral, em duas épocas de colheita. João Pessoa, EMEPA, 1999.

MARTIN, F.W. Tropical yams and their potential. Washington: USDA, 1976. 40 p. (USDA. Agriculture Handbook, 495).

MARTIN, F.W. Yam production methods. Washington: USDA, 1972. 17 p. (USDA. Agricultural Research, 147).

MATIAS, E.C.; ALMEIDA, A.M. Efeitos de fontes de matéria orgânica na cultura do inhame. João Pessoa: EMEPA - PB, 1985, 36 p.

MATIAS, E.C. Adubação mineral e orgânica na cultura do inhame (Dioscorea cayennensis Lam.) em podzólico vermelho amarelo. Recife: UFRPE, 1989. 72 p. (Tese mestrado).

MATOS, A.T.; SEDIYAMA, M.A.N.; VIDIGAL, S.M.; GARCIA, N.C.P. Efeito da adubação orgânica sobre algumas características de um Podzólico Vermelho Amarelo câmbico cultivado com cenoura: II. segundo cultivo. In: CONGRESSO BRASILEIRO DE CIÊNCIA DO SOLO, 26., 1997, Rio de Janeiro. Resumos... Rio de Janeiro: SBCS, 1997. p. 237.

MENDES, R.A. Cultivando inhame ou cará-dacosta. Cruz das Almas: EMBRAPA CNPMF, 1982. 16 p. (EMBRAPA-CNPMF.Circular Técnica, 4). OBIGBESAN, G.O.; AGBOOLA, A.A. Uptake and distribution of nutrients by yams (Dioscorea spp.) Exploration Agricultural, v. 14, n. 1,p. 349-345, 1978.
OLIVEIRA FILHO, J.M.; CARVALHO, M.A.; GUEDES, G.A.A. Matéria orgânica no solo. Informe Agropecuário, Belo Horizonte, v. 13, n. 147, p. 22-36, 1987.

PEREIRA, E.B.; CARDOSO, A.A.; LOURES, E.G.; KUGIKARI, Y. Viabilidade econômica do composto orgânico na cultura do feijão. CariacicaES: EMCAPA, junho 1985. 4 p (Comunicado técnico).

SANTOS, E.S. Inhame (Dioscorea spp.): aspectos básicos da cultura. João Pessoa: EMEPA-PB, SEBRAE. 158 p. 1996.

SANTOS, E.S.; MATIAS, E.C.; MELO, A.S. Efeitos de fontes e doses de matéria orgânica na produtividade de inhame. João Pessoa: EMEPAPB,1998. 18 p. (Boletim de Pesquisa).

SILVA, A.A. Cultura do cará-da-costa (Dioscorea cayennensis Lam.) var. Rotundata Poir. 2 ed. Fortaleza: BNB/ETENE, 1983. 97 p.

SOUTO, J.S. Adubação mineral e orgânica do cará da costa (Dioscorea cayennensis Lam.). Areia: CCA-UFPB, 1989, 57 p. (Tese mestrado). 